\title{
Preparation of Aligned ZnO Nanorod Arrays on Sn-Doped ZnO Thin Films by Sonicated Sol-Gel Immersion Fabricated for Dye-Sensitized Solar Cell
}

\author{
I. Saurdi, ${ }^{1,2}$ M. H. Mamat, ${ }^{1}$ M. F. Malek, ${ }^{1}$ and M. Rusop ${ }^{1,3}$ \\ ${ }^{1}$ NANO-ElecTronic Centre, Faculty of Electrical Engineering, Universiti Teknologi MARA, 40450 Shah Alam, Selangor, Malaysia \\ ${ }^{2}$ Faculty of Electrical Engineering, UiTM Sarawak, Campus Kota Samarahan, Jalan Meranek, Sarawak, Malaysia \\ ${ }^{3}$ NANO-SciTech Centre, Institute of Science, Universiti Teknologi MARA, 40450 Shah Alam, Selangor, Malaysia \\ Correspondence should be addressed to I. Saurdi; saurdy788@gmail.com
}

Received 31 January 2014; Revised 12 June 2014; Accepted 16 June 2014; Published 14 July 2014

Academic Editor: Markku Leskela

Copyright (c) 2014 I. Saurdi et al. This is an open access article distributed under the Creative Commons Attribution License, which permits unrestricted use, distribution, and reproduction in any medium, provided the original work is properly cited.

\begin{abstract}
Aligned $\mathrm{ZnO}$ Nanorod arrays are deposited on the Sn-doped $\mathrm{ZnO}$ thin film via sonicated sol-gel immersion method. The structural, optical, and electrical properties of the Sn-doped $\mathrm{ZnO}$ thin films were investigated. Results show that the Sn-doped $\mathrm{ZnO}$ thin films with small grain size $(\sim 20 \mathrm{~nm})$, high average transmittance $(96 \%)$ in visible region, and good resistivity $7.7 \times 10^{2} \Omega \cdot \mathrm{cm}$ are obtained for 2 at.\% Sn doping concentration. The aligned $\mathrm{ZnO}$ nanorod arrays with large surface area were also obtained for 2 at.\% $\mathrm{Sn}$-doped $\mathrm{ZnO}$ thin film. They were grown on sol-gel derived $\mathrm{Sn}$-doped $\mathrm{ZnO}$ thin film, which acts as a seed layer, via sonicated sol-gel immersion method. The grown aligned $\mathrm{ZnO}$ nanorod arrays show high transmittance at visible region. The fabricated dyesensitised solar cell based on the 2.0 at.\% Sn-doped $\mathrm{ZnO}$ thin film with aligned $\mathrm{ZnO}$ nanorod arrays exhibits improved current density, open-circuit voltage, fill factor, and conversion efficiency compared with the undoped $\mathrm{ZnO}$ and 1 at.\% Sn-doped $\mathrm{ZnO}$ thin films.
\end{abstract}

\section{Introduction}

One-dimensional $\mathrm{ZnO}$ semiconductor has been widely studied because it exists in several advantageous nanostructures, such as nanosheet, nanowires (NWs), and nanoflowers which have attracted much attention for various applications because of their unique properties [1]. Zinc oxide $(\mathrm{ZnO})$ is a wide-bandgap II-VI compound with a $3.37 \mathrm{eV}$ direct bandgap and $60 \mathrm{meV}$ of free-exciton excitation energy at room temperature. $\mathrm{ZnO}$ can be synthesized in many forms of nanostructures via simple and low-cost techniques such as sol-gel and solution-based methods. Various forms of $\mathrm{ZnO}$ morphologies and sizes significantly contribute to the novel characteristics of the devices. Many researchers have employed various kinds of $\mathrm{ZnO}$ nanostructures [2-4] in dyesensitized solar cells, which show a significant improvement in the photovoltaic characteristics of the DSSCs. Aligned zinc oxide $\mathrm{ZnO}$ nanorod arrays nanostructures provide large surface area and superior carrier transport properties for DSSCs $[5,6]$. In addition, the use of a lattice-matched and conducting buffer layer is a feasible way to grow nanorods and NWs, instead of using other materials such as sapphire, that are insulators and expensive. Therefore, the $\mathrm{ZnO}$ nanorods and $\mathrm{NW}$ arrays grown on metal doped $\mathrm{ZnO}$ seed layer are extensively studied. Moreover, Sn-, Al-, Ga-, and In-doped $\mathrm{ZnO}$ thin films that show high crystalline structure are useful for practical application on various electronic devices such as solar cells and electroluminescence displays [7-9]. Metaldoped $\mathrm{ZnO}$ can be prepared via several techniques such as atomic layer deposition [10], chemical vapour deposition [11], sol- gel [12], pulsed laser deposition [13], RF sputtering [14], spray pyrolysis [15], and so forth. Among these techniques, sol-gel is the most effective in terms of cost and economical production.

In recent years, the $\mathrm{ZnO}$ nanorods grown on $\mathrm{Al}$-doped $\mathrm{ZnO}(\mathrm{AZO})$ seed layers have been investigated [16, 17]. 
Yang et al. [18] reported the influence of Sn-doping on $\mathrm{ZnO}$ nanorod prepared by hydrothermal method in aqueous solution using zinc nitrate as precursor; however, $\mathrm{ZnO}$ nanorods grown on Sn-doped $\mathrm{ZnO}$ as seed layers and applied in DSSCs are rarely reported. Moreover, Sn materials, which are originally from group IV elements, exhibit advantages because of their two more extra electrons that can be substituted into $\mathrm{ZnO}$, thereby contributing to double charge carriers. In this study, Sn-doped $\mathrm{ZnO}$ films were prepared by sol-gel process. The effects of Sn-doped concentrations on structural, electrical, and optical properties of the as-prepared Sn-doped $\mathrm{ZnO}$ thin films were investigated. In addition, the aligned $\mathrm{ZnO}$ nanorod arrays were grown on Sn-doped $\mathrm{ZnO}$ films using a sonicated sol-gel immersion method. The optical and morphological properties of the aligned $\mathrm{ZnO}$ nanorod arrays were also studied. The aligned $\mathrm{ZnO}$ nanorod arrays were used as photoanodes in DSSC and their photovoltaic were evaluated.

\section{Experimental Detail}

The Sn-doped thin films and aligned $\mathrm{ZnO}$ nanorods grown on $\mathrm{Sn}$-doped $\mathrm{ZnO}$ seed layer were prepared and grown by sonicated sol-gel immersion. Zinc acetate dehydrate $(0.4 \mathrm{M}$, $\left.\mathrm{Zn}\left(\mathrm{CH}_{3} \mathrm{CO}_{2}\right)_{2} \cdot 2 \mathrm{H}_{2} \mathrm{O}\right)$ was first dissolved in a 2-methoxyethanol-monoethanolamine with molar ratio $1: 1$ at ambient conditions. Appropriate amounts of tin doping were doped by adding tin(IV) chloride pentahydrate to the precursor solution. To utilize the Sn-doped $\mathrm{ZnO}$ thin films as a seeded layer for $\mathrm{ZnO}$ nanorod arrays growth, three solutions with doping concentration $S n / Z n=0,1,2$ at.\% were prepared. The effects of Sn doping concentration on the structural, optical, and electrical properties of the Sn-doped $\mathrm{ZnO}$ thin films and the aligned $\mathrm{ZnO}$ nanorod growth at different concentrations $(0,1$, and 2 at.\%) were investigated in DSSC. The solution was stirred and heated for $3 \mathrm{~h}$ before aging for 24 hours at room temperature. The $\mathrm{Sn}$-doped $\mathrm{ZnO}$ thin films were spincoated on glass and ITO substrates at $3000 \mathrm{rpm}$ for $1 \mathrm{~min}$. Each layer of deposited thin film was preheated in air at $150^{\circ} \mathrm{C}$ to evaporate the solvent. The coating procedure was repeated a few times to increase the film thickness. The thin film was then postheated at $500^{\circ} \mathrm{C}$ for $1 \mathrm{~h}$ in air using an electronic furnace. Corresponding to the different Sndoped $\mathrm{ZnO}$ concentrations $(0,1$, and 2 at. \%), the obtained thin films were labelled as samples $P, Q$, and $R$, respectively. The $\mathrm{ZnO}$ nanorod arrays were deposited on $\mathrm{Sn}$-doped $\mathrm{ZnO}$ thin film ITO coated glass substrates using zinc acetate solution. The zinc acetate solution was composed of zinc acetate dihydrate, hexamethylenetetramine, and deionized water. The solution was sonicated for $30 \mathrm{~min}$ before stirring and aging for $3 \mathrm{~h}$. The $\mathrm{ZnO}$ nanorod arrays were grown in water bath at $95^{\circ} \mathrm{C}$. The seed layered, ITO-coated glass substrates were immersed into the zinc acetate solution using Schott bottles. The bottles were placed inside the water bath instrument for $1 \mathrm{~h}$ for nanorod deposition. After the immersion process, the samples were taken from the bottles and dried in air for $15 \mathrm{~min}$. The samples were annealed in air at $500^{\circ} \mathrm{C}$.
To fabricate DSSCs, $\mathrm{ZnO}$ nanorod electrode was immersed in $0.5 \mathrm{mM}$ ethanolic solution of $\left(\mathrm{Ru}\left[\mathrm{LL}^{\prime}(\mathrm{NCS})_{2}\right]\right.$, $\mathrm{L}=2,2^{\prime}$-bipyridyl-4,4'-dicarboxylic acid, $\mathrm{L}^{\prime}=2,20$-bipyridyl$4,4^{\prime}$-ditetrabutylammonium carboxylate) dye (N719) at room temperature for $24 \mathrm{~h}$. Pt $(60 \mathrm{~nm}$ thick) sputtered on ITO was used as an electrochemical catalyst for the counter electrode. The substrate with $\mathrm{ZnO}$ nanorod electrode and dye was bonded with a sputtered counter electrode using holt-melt spacer. Sealing was accomplished by pressing the two electrodes at approximately $100^{\circ} \mathrm{C}$ for a few seconds. The electrolytes, composed of $0.5 \mathrm{M} \mathrm{Lil,} 0.05 \mathrm{M} \mathrm{I}_{2}$, and $0.5 \mathrm{M}$ 4-tert-butyl pyridine (TBP) in acetonitrile, were then introduced into the cell by capillary forces through two holes drilled in the counterelectrode. The holes were covered and sealed to prevent fluid-type electrolyte leakage. The active area of the DSSC device measured using a black mask was $0.25 \mathrm{~cm}^{2}$. The fabricated DSSC of aligned $\mathrm{ZnO}$ nanorod arrays were labelled as samples ZP, ZQ, and ZR. Solar simulator (Bukuh Keiki EP-2000), JASCO UV-VIS/NIR spectrophotometer (V-670 EX), surface profiler (Veeco Dektak 150), X-ray diffractometer (XRD, Rigaku Co., D/ MAX-2000), two-probe current-voltage (I-V) measurement (Bukuh Keiki EP-2000), field-emission scanning electron microscopic (FESEM, ZEISS Supra 40VP), and energy-dispersive analyser X-ray spectroscope (EDX) were used to characterize the electronic, optical, structural, electrical, and surface properties $\mathrm{ZnO}$ nanorod arrays and Sn-doped $\mathrm{ZnO}$ thin films.

\section{Result and Discussion}

Figure 1 shows the FESEM images of the Sn-doped $\mathrm{ZnO}$ thin film and the existence of $\mathrm{Sn}$ dopant in $\mathrm{Sn}$-doped $\mathrm{ZnO}$ thin film was proven by EDX result Figure 1(d). Sn-doped $\mathrm{ZnO}$ thin films with flat surface morphology and uniform grain size were prepared by the sol-gel technique. The particle size of the thin film was obviously influenced by the Sn-doped concentration $(36,25$, and $20 \mathrm{~nm}$ for 0,1 , and 2 at.\%, resp.) as estimated in the obtained FESEM images. This phenomenon can be due to substitutional doping, which was attributed to different ionic radii of $\mathrm{Sn}^{4+}$ ions and $\mathrm{Zn}^{2+}$ ion. $\mathrm{Sn}^{4+}$ ion possesses $0.067 \mathrm{~nm}$ ionic radius, which is smaller than $\mathrm{Zn}^{2+}$ $(0.074 \mathrm{~nm})$, thereby retarding the growth process of $\mathrm{ZnO}$ crystallization $[19,20]$ and indicating that the $\mathrm{Zn}^{2+}$ is successfully substituted by $\mathrm{Sn}^{4+}$ at the lattice point of $\mathrm{ZnO}$ [21].

The Sn-doped concentration can also affect the electrical properties of $\mathrm{ZnO}$ thin films, in which more electron are produced whenever $\mathrm{Sn}$ concentration is increased up to 2 at.\%. Two- probe system measurement was employed to study the $I-V$ characteristics of $\mathrm{ZnO}$ thin films. Figure 2 shows the $I-V$ curve of Sn-doped $\mathrm{ZnO}$ thin films at $-10 \mathrm{~V}$ to $10 \mathrm{~V}$ applied voltage. All of the prepared thin films show good contact with Au. Furthermore, $\mathrm{ZnO}$ thin film doped with 2 at.\% Sn shows the highest current intensity among all of the $\mathrm{Sn}$-doped $\mathrm{ZnO}$ thin films, reflecting the best optimal electrical properties. By contrast, the undoped $\mathrm{ZnO}$ film shows the lowest of current intensity, indicating poor electrical properties. Moreover, the resistivity of the $\mathrm{ZnO}$ thin 


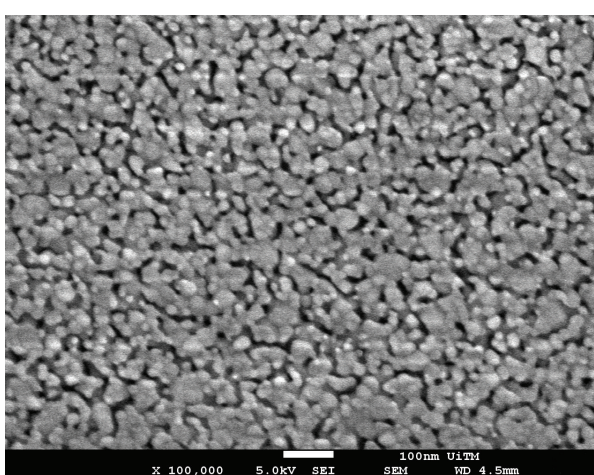

(a)

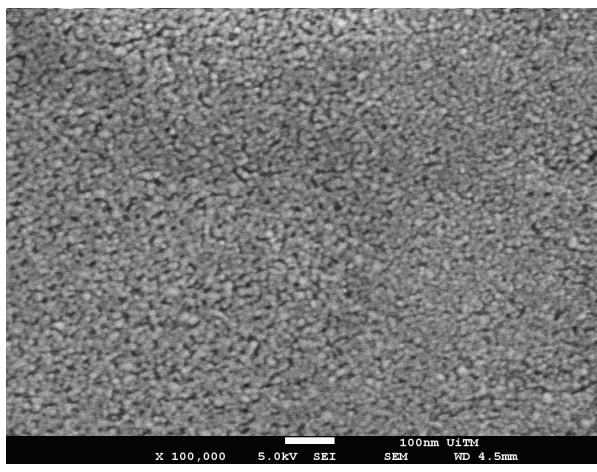

(c)

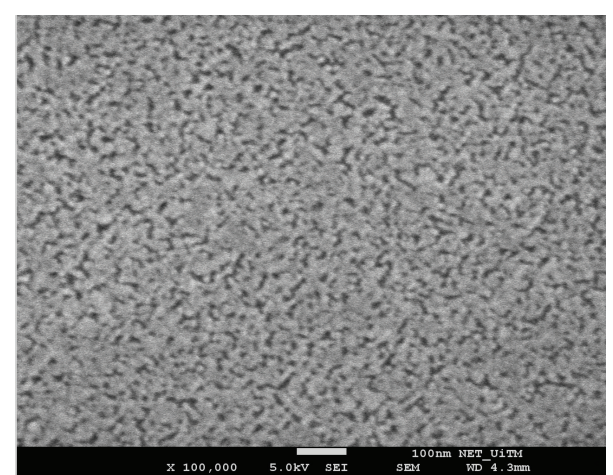

(b)

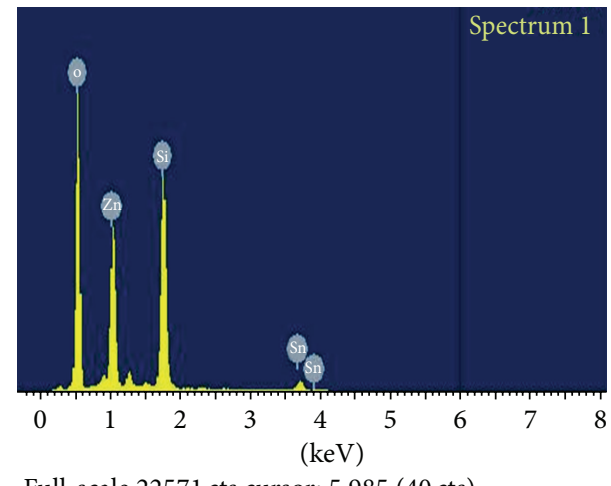

Full-scale 22571 cts cursor: 5.985 ( 40 cts)

(d)

FIGURE 1: FESEM images of the Sn-doped ZnO films: (a) sample $P$, (b) sample $Q$ (c), sample $R$, and (d) EDX at 2 at.\% Sn-doped ZnO thin film.

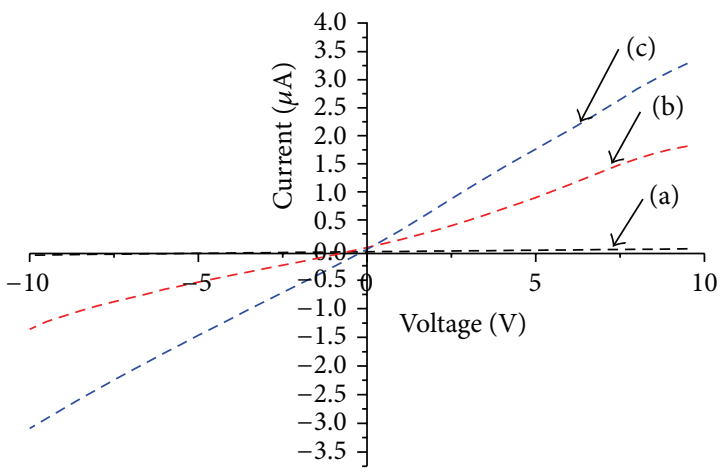

- - - (a) Undoped $\mathrm{ZnO}$

- - - (b) 1 at.\% Sn

-.. (c) 2 at.\% $\mathrm{Sn}$

Figure 2: $I-V$ curves of the $\mathrm{ZnO}$ thin films with different $\mathrm{Sn}$ concentrations: (a) sample $P, 0$ at.\% Sn, (b) sample $Q, 1$ at.\% Sn, and (c) sample $R, 2$ at.\% $\mathrm{Sn}$.

films decreases with the increase in doping concentration from 0 at.\% to 2 at.\% (Figure 2), which also shows the lowest resistivity $\left(7.7 \times 10^{2} \Omega \cdot \mathrm{cm}\right)$. Furthermore, the decrease in resistivity of $\mathrm{Sn}$-doped thin film from 0 at.\% to 2 at.\% was due to substitutional doping of the $\mathrm{ZnO}$ structure [22]. Therefore, two free electrons produced from the substitutional doping increased carrier's concentration in the films, which also affect the electron mobility [23]. This result is similar to the one reported by Tsay et al. [24]. In addition, the grain size for sample Q-Sn 1 at.\% and sample $R-S n-2$ at.\% was smaller than that of the undoped $\mathrm{ZnO}$ film. The small grain size can be due to an increment in the transmission line, which is probably caused by the generation of large number of grain boundaries [20].

The transmittance spectra of the $\mathrm{ZnO}$ films were measured using UV-Vis-NIR spectrophotometer. As shown in Figure 3(a), all of the thin films exhibit high transparency (>90\%) from $400 \mathrm{~nm}$ to $800 \mathrm{~nm}$ and high absorption edges in the UV region. However, the optical transmittance showed the value of UV region about $65-70 \%$. From the result of EDX in Figure 1(d), there exist four elements which are silicon $(18.80 \%)$, zinc $(16.32 \%)$, oxygen $(62.93 \%)$, and tin (Sn) $(1.95 \%)$ in atomic percentage. The peak of silicon comes from glass substrate of $\mathrm{Sn}$-doped $\mathrm{ZnO}$ films. The ratio of $\mathrm{ZnO}: \mathrm{O}$ is about $1: 3.856$, whereby the theoretical value of 1 is as expected for $\mathrm{ZnO}$. Therefore, high transparency at $\mathrm{UV}$ region might be due to the unreacted zinc along with $\mathrm{ZnO}$ films and similar phenomenon has been reported by Shelke et al. [21] and $\mathrm{Oh}$ et al. [25]. The transmittance at 2 at.\% 


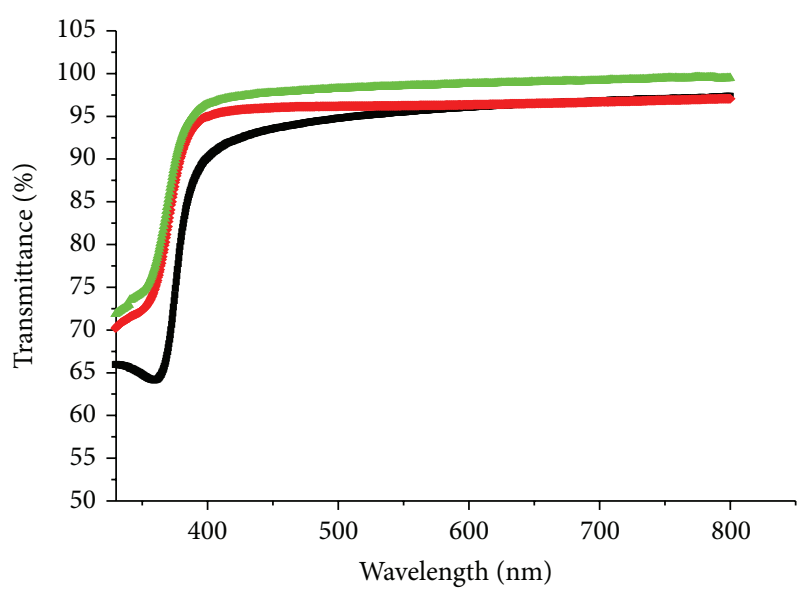

- (a) Undoped $\mathrm{ZnO}$

- (b) 1 at.\% Sn

(c) 2 at. $\% \mathrm{Sn}$

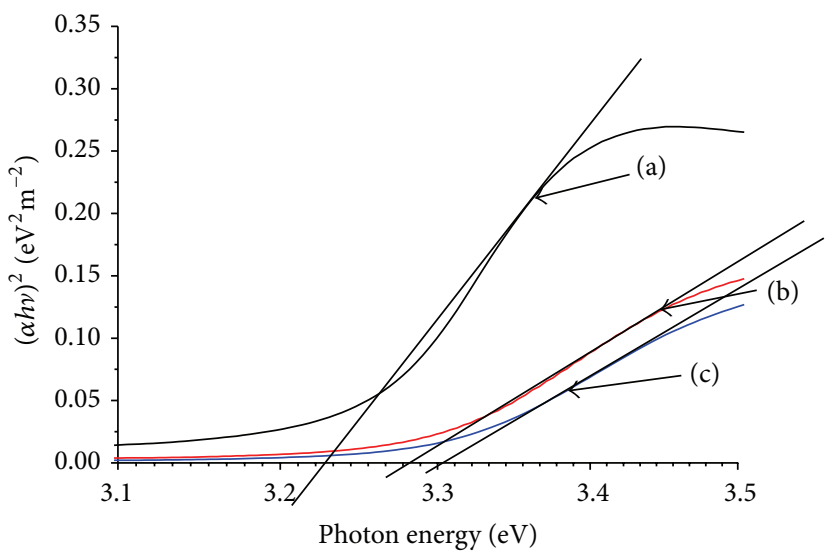

(a) Undoped Z
(b) 1 at.\% Sn
(c) 2 at.\% Sn

(a)

(b)

FIgUre 3: (a) Transmittance and (b) optical band gap energy using Tauc's plot.

Sn-doped $\mathrm{ZnO}$ thin film exhibited 96\% average transparency, which was higher than that of the undoped and 1 at.\% Sn-doped $\mathrm{ZnO}$ thin film. The high transmittance of thin film can be due to its small surface roughness, thereby suppressing the growth of $\mathrm{ZnO} \mathrm{Sn}$ dopants and forming flat and fine surfaces [18]. Moreover, the obtained results are comparable with those obtained by Tsay et al. [24] and Pan et al. [26]. High transparency of thin film is useful as window layer in solar cell application. Meanwhile, the optical band gap values of the $\mathrm{Sn}$-doped $\mathrm{ZnO}$ were obtained using transmittance data and plotting $(\alpha h \nu)^{2}$ versus photon energy graphs that also called Tauc's plot. From Tauc's plot in Figure 3(a), the results revealed the band gap of $3.23 \mathrm{eV}$ for undoped which was found to be increased to $3.28 \mathrm{eV}$ and 3.30 after Sn doping 1 at.\% and 2 at.\%, respectively. Therefore, the thin film tends to blue-shift when the doping concentration increases because of the increase in electron concentration increase and band gap energy broadening. This phenomenon is observed because of the electron with adequate energy supplied from photon energy jumps from the valence band to the conduction band. Therefore, at high Sn concentrations, the $\mathrm{Sn}$-doped $\mathrm{ZnO}$ thin film exhibits relatively broadband gap energies compared with those of the undoped $\mathrm{ZnO}$ film. Anders et al. [27] reported that the broadening of optical band gap energy can be attributed to Burstein-Moss shift.

Figure 4 shows the surface morphologies of the $\mathrm{ZnO}$ nanorod grown on $\mathrm{Sn}$-doped $\mathrm{ZnO}$ thin film (0, 1, and 2.0 at.\%). The $P, Q$, and $R$ samples were employed as the seed layer for the growth of the aligned $\mathrm{ZnO}$ nanorod. It can be seen that the seed layer with different concentrations of Sn-doped $\mathrm{ZnO}$ influenced the morphology and density of the $\mathrm{ZnO}$ nanorod arrays. The diameter of the aligned $\mathrm{ZnO}$ nanorod grown on sample $R$ is smaller than the aligned $\mathrm{ZnO}$ nanorod grown on sample $P$ and $Q$. This result can be due to the dependence of the diameter of $\mathrm{ZnO}$ nanorod and the distances between $\mathrm{ZnO}$ nanorods on the grain size and interspaces of the seed layer, respectively, which are confirmed by the results shown in Figure 1 and also similar to the results reported by Zhang and Que [28]. It can be seen that the aligned $\mathrm{ZnO}$ nanorods grown on ITO substrate are crystallized along the $\mathrm{ZnO}$ [0001] direction, forming hexagonal prisms that are also reported by others $[29,30]$. Moreover, the aligned $\mathrm{ZnO}$ nanorod grown on sample $R$ is the longest among all of the samples. Smaller nanorods and large interspaces between nanorods indicate high surface area as shown in Figures 4 and 5. The nanorod growth is possibly related to the amount of dopants in the $\mathrm{ZnO}$ thin films, probably because of high electron concentration in 2 at.\% Sn-doped $\mathrm{ZnO}$ sample, thereby facilitating the growth of aligned $\mathrm{ZnO}$ nanorod arrays [30]. Furthermore, relatively high quantity of the grains is found within the unit area of sample $R$ compared with that in samples $P$ and $Q$ (Figure 1). A larger number of $\mathrm{ZnO}$ nanorods are grown on the sample with larger interspaces between $\mathrm{ZnO}$ nanorods. In addition, sample $R$ smaller grain size leading to smaller $\mathrm{ZnO}$ nanorod growth, whereas bigger grain size is observed for samples $P$ and $Q$ leading to broader $\mathrm{ZnO}$ nanorod diameter with denser of $\mathrm{ZnO}$ nanorod arrays. The longest $\mathrm{ZnO}$ nanorod arrays were found in sample $R$, followed by samples $Q$ and $P$. Thus, the larger the grain size the shorter the $\mathrm{ZnO}$ nanorod arrays. Based on above results and discussion, the aligned $\mathrm{ZnO}$ nanorod grown on sample $R$ is suitable for the DSSCs. Moreover, the small nanorods and large interspaces between nanorods are better for dye absorption in DSSC application. The transmittance spectra of $\mathrm{ZnO}$ nanorod at different Sn-doped $\mathrm{ZnO}$ concentrations (0, 1, and 2 at.\%) seeded layer (no N719 and electrolytes) are shown in Figure 6. All of the nanorod exhibit high transparency (50\% to 60\%) from $400 \mathrm{~nm}$ to $800 \mathrm{~nm}$. The regular wave shape of the transmittance suggests that the thickness of $\mathrm{ZnO}$ nanorod 


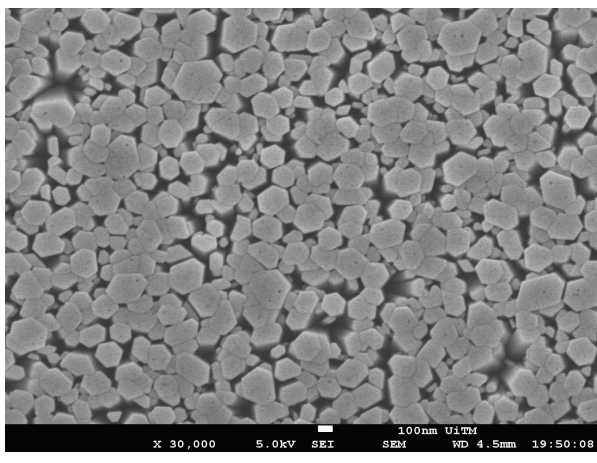

(a)

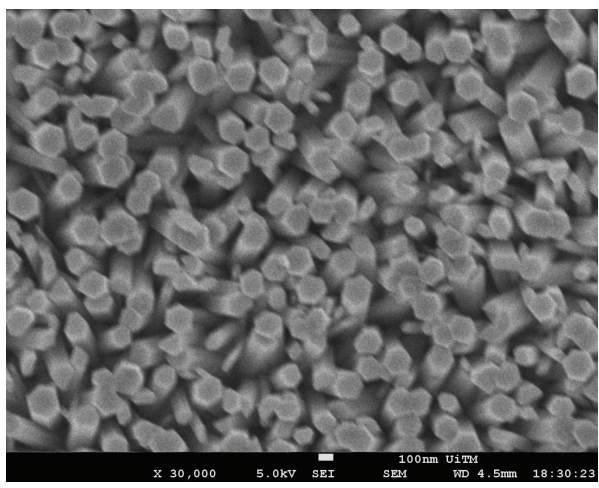

(c)

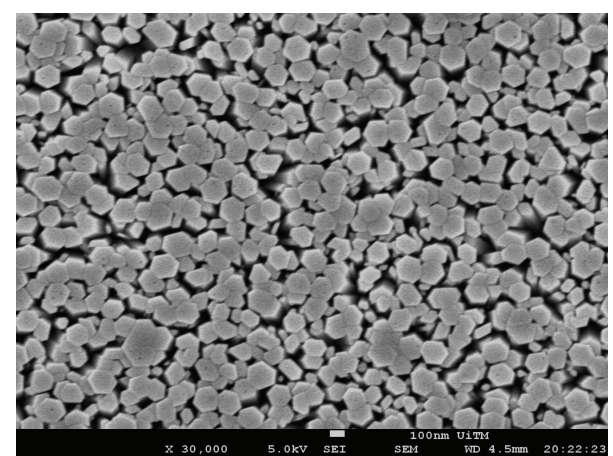

(b)

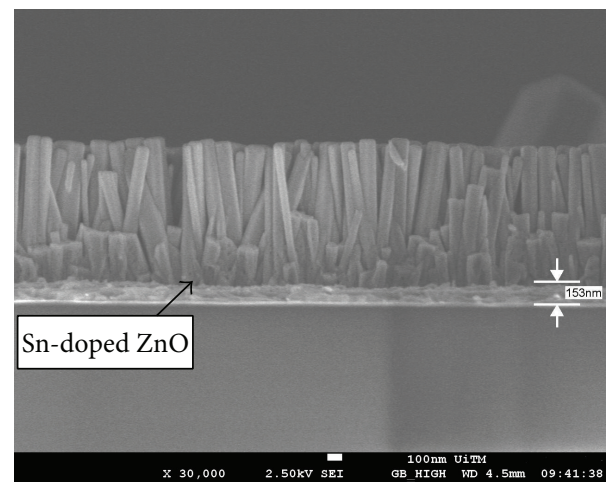

(d)

FIGURE 4: FESEM images of the $\mathrm{ZnO}$ nanorods grown on the $\mathrm{Sn}$-doped $\mathrm{ZnO}$ seed layer: (a) sample $P$, (b) sample $Q$, and (c) sample $R$. (d) Cross-section of $\mathrm{ZnO}$ nanorod sample $R$.

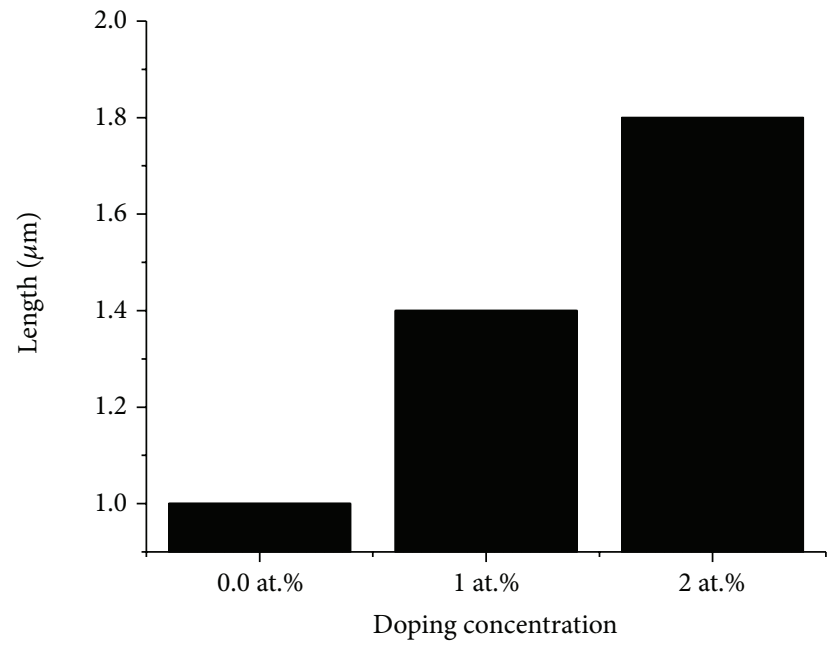

Figure 5: Relationship between the length of the aligned $\mathrm{ZnO}$ nanorods arrays and Sn doping concentration.

arrays is uniform, which is also confirmed in Figure 4. The transparency of the $\mathrm{ZnO}$ nanorods for samples $P$ and $Q$ is approximately $60 \%$ and $55 \%$, respectively. Meanwhile, the transparency of sample $R$ is $\sim 51 \%$, which can be due to surface roughness and verticality of the $\mathrm{ZnO}$ nanorod. High surface

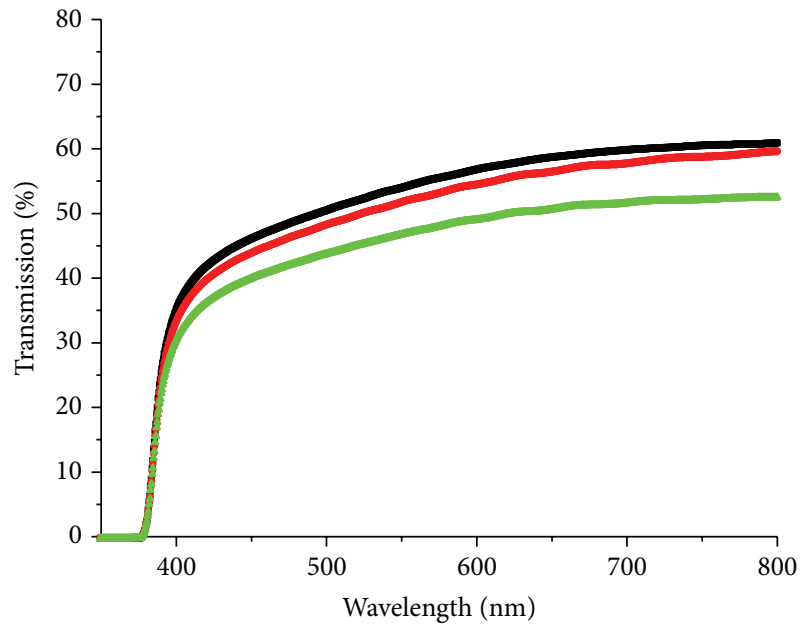

- ZnO nanorod grown on sample $P$

- ZnO nanorod grown on sample $Q$

$\triangle \mathrm{ZnO}$ nanorod grown on sample $R$

FIGURE 6: Optical transmittance spectra of the $\mathrm{ZnO}$ nanorods grown on samples $P, Q$, and $R$.

roughness and poor verticality of the $\mathrm{ZnO}$ nanorod can cause high light scattering and decrease transmittance. In DSSCs the dye absorption by the films is one of the main factors in 


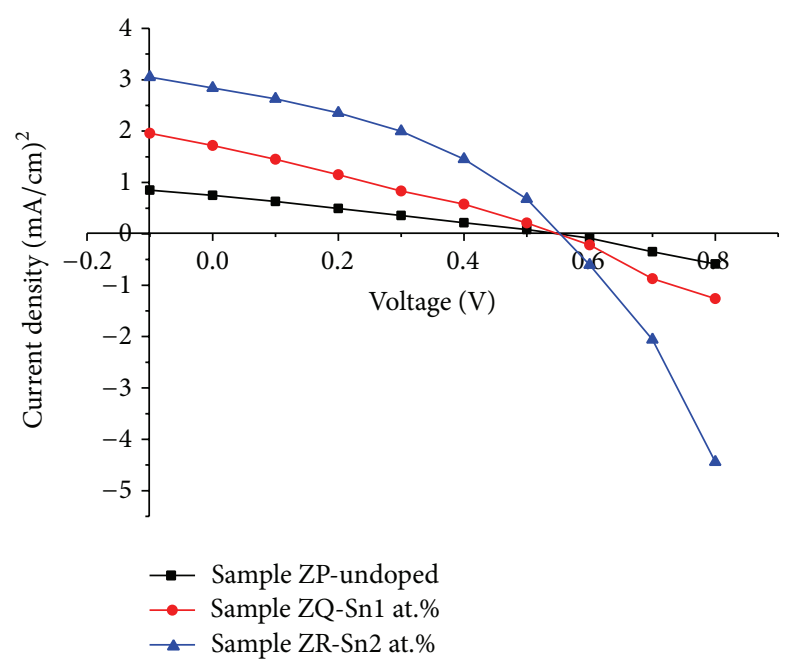

FIgURE 7: $I-V$ characteristics of fabricated DSSCs under light density $\left(100 \mathrm{~mW} / \mathrm{cm}^{2}\right)$.

determining the photon energy absorbed from sunlight and transformed as electric current [31-33].

Figure 7 shows the $I-V$ characteristics of the $\mathrm{ZnO}$ nanorod DSSC grown at different $\mathrm{Sn}$-doped $\mathrm{ZnO}$ concentrations. To investigate the performances of the DSSCs, opencircuit voltage $\left(V_{\mathrm{OC}}\right)$, short-circuit density $\left(J_{\mathrm{SC}}\right)$, fill factor $(\mathrm{FF})$, and overall conversion efficiency $(\eta)$ were calculated as

$$
\eta(\%)=\frac{\left(J_{\mathrm{SC}}\right) \times\left(V_{\mathrm{OC}}\right) \times \mathrm{FF} \times 100}{P_{\mathrm{in}}} .
$$

The aligned $\mathrm{ZnO}$ nanorod photoanode (sample $\mathrm{ZR}$ ) grown on 2 at.\% $\mathrm{Sn}$-doped $\mathrm{ZnO}$ film showed higher efficiency than the $\mathrm{ZnO}$ nanorod photoanode grown on 1 at.\% Sndoped and undoped $\mathrm{ZnO}$ film. Thus, at 2 at.\%, the long $\mathrm{ZnO}$ nanorods with large surface area are better than $P$ and $Q$ samples. Higher dye absorption in films contributes to the improvement of the photovoltaic properties of the DSSCs. The high density of $\mathrm{ZnO}$ nanorod with more pores and large surface can enhance the absorption of photon energy because of high dye absorbed [28, 29]. Meanwhile, high density with less pores and low surface area can cause low dye absorption and thus less photon generation whenever the sunlight illuminates the DSSC. Thus, the photovoltaic properties of $\mathrm{ZnO}$ nanorod photoanode on sample $\mathrm{ZP}$ (undoped) and sample ZQ (1 at.\% Sn) were lower than sample ZR ( 2 at.\% Sn). Table 1 summarizes the photovoltaic performance of the fabricated DSSCs. The $J_{\mathrm{sc}}, V_{\mathrm{oc}}$, and energy conversion efficiency $\eta$ of DSSC of ZnO nanorod photoanode grown at 2 at.\% Sn-doped $\mathrm{ZnO}$ film were increased. These increases are due to the large surface area of $\mathrm{ZnO}$ nanorod, thereby enriching light absorption in high absorption of the N719, which contributes to high photocurrent density. In addition, the multiscattering effect in nanorod can enhance the incident light. The seeded layer of 2 at.\% Sn-doped $\mathrm{ZnO}$ thin film with low resistivity is also suitable as a buffer layer, in which the recombination between $\mathrm{ZnO}$ nanorod as a photoanode and ITO electrode is reduced. Meanwhile, the $J_{\mathrm{sc}}$

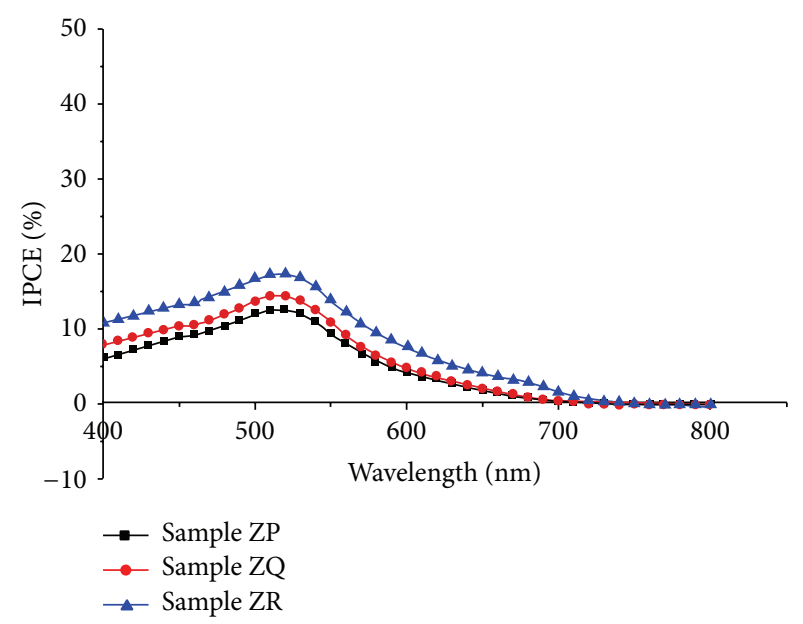

FIGURE 8: IPCE curve of ZnO nanorod DSSC grown on Sn-doped $\mathrm{ZnO}$ at different concentrations.

and $V_{\mathrm{oc}}$ for 0 and 1 at.\% DSSC with $\mathrm{ZnO}$ nanorod are smaller than those of the $\mathrm{ZnO}$ nanorod grown on 2 at.\% Sn-doped $\mathrm{ZnO}$ film. Therefore, the compact structure of $\mathrm{ZnO}$ nanorod grown on 0 and 1 at.\% films decreases $J_{\mathrm{sc}}$ and $V_{\mathrm{oc}}$ as well as the performance of DSSCs, which is attributed to less absorption of dye and low photon generation due to high recombination at $\mathrm{ZnO}$ nanorod surface. Furthermore, the improvement in current density, fill factor, and conversion efficiency, for $\mathrm{ZnO}$ nanorod grown on 2 at.\% Sn-doped $\mathrm{ZnO}$ film, were increased from 0.749 to $2.84,0.260$ to 0.381 , and $0.107 \%$ to $0.599 \%$, respectively, compared with those of the $\mathrm{ZnO}$ nanorod on undoped film and 1 at.\% Sn-doped $\mathrm{ZnO}$ film. The improvement in film quality is due to high surface area and high length of $\mathrm{ZnO}$ Nanorod grown on 2 at.\% Sndoped $\mathrm{ZnO}$ film. This improvement enhanced photovoltaic characteristics of the DSSC.

Figure 8 shows the IPCE of the aligned $\mathrm{ZnO}$ nanorod grown on Sn-doped films at different Sn concentrations. The IPCE is the ratio of the number of electrons generated by light in the external circuit to the number of incident photons. As shown in Figure 5, the IPCE of the $\mathrm{ZnO}$ nanorod grown at 2 at.\% Sn-doped $\mathrm{ZnO}$ thin film is approximately $18 \%$. The IPCE of $\mathrm{ZnO}$ nanorod grown on 1 and 0 at.\% Sndoped are lower than that of the $\mathrm{ZnO}$ nanorods grown on 2 at.\% Sn-doped $\mathrm{ZnO}$ thin film. With the enhanced $\mathrm{ZnO}$ nanorod growth from 0 at.\% to 2 at.\% Sn-doped film the IPCE values increase from $10 \%$ up to $18 \%$ at $520 \mathrm{~nm}$. These results confirmed the relatively high current density of the $\mathrm{ZnO}$ nanorod grown on sample $R$. The relatively low IPCE for the two $\mathrm{ZnO}$ nanorods (samples $P$ and $Q$ ) can be due to high density of $\mathrm{ZnO}$ nanorods with less pores and low surface area, which contributed to less dye absorption in the films. Moreover, the relatively high IPCE of $\mathrm{ZnO}$ nanorod growth on 2 at.\% Sn-doped $\mathrm{ZnO}$ film is attributed to the dye absorption caused by high surface area with more pores of film, which consequently increases the incident light intensity in the N719 dye. 
TABLE 1: Photovoltaic performance of $\mathrm{ZnO}$ nanorod DSSCs fabricated on different $\mathrm{Sn}$-doped $\mathrm{ZnO}$.

\begin{tabular}{lcccc}
\hline Type of photoanode & $J_{\text {sc }}\left(\mathrm{mA} / \mathrm{cm}^{2}\right)$ & $V_{\mathrm{oc}}(\mathrm{v})$ & Fill factor & Efficiency $(\%)$ \\
\hline Sample ZP-0 at.\% & 0.749 & 0.548 & 0.260 & 0.107 \\
Sample ZQ-1 at.\% & 1.719 & 0.549 & 0.265 & 0.250 \\
Sample ZR-2 at.\% & 2.840 & 0.552 & 0.381 & 0.599 \\
\hline
\end{tabular}

\section{Conclusion}

In this study, the effects of Sn-doped $\mathrm{ZnO}$ thin films on the structural, optical, and electronic properties of $\mathrm{ZnO}$ nanorod were investigated. The grain size of nanostructured $\mathrm{ZnO}$ thin films decreases with the increase in doping concentration. The 2 at.\% Sn-doped $\mathrm{ZnO}$ thin film shows small grain size, high transmittance, and low resistivity. Moreover, the $\mathrm{ZnO}$ nanorods grown on $\mathrm{Sn}$-doped $\mathrm{ZnO}$ seed layer exhibit high transmittance in the visible region. Furthermore, the $\mathrm{ZnO}$ nanorods grown on 2 at.\% Sn-doped $\mathrm{ZnO}$ thin film possess large surface area with longer aligned $\mathrm{ZnO}$ nanorods. Compared with the undoped film, the improvement of current density, fill factor, and conversion efficiency for $\mathrm{ZnO}$ nanorod grown on 2 at.\% $\mathrm{Sn}$-doped $\mathrm{ZnO}$ film was increased from 0.749 to $2.84,0.260$ to 0.381 , and $0.107 \%$ to $0.599 \%$, respectively. With the increase in $\mathrm{ZnO}$ nanorod growth from 0 to 2 at.\% Sn-doped film, the IPCE values increase from $10 \%$ to $18 \%$ at $520 \mathrm{~nm}$. The improvement in film quality is due to high density, more pores, and long $\mathrm{ZnO}$ nanorod grown on 2 at.\% $\mathrm{Sn}$-doped $\mathrm{ZnO}$ film. These improvements contributed to the enhancement of the photovoltaic properties of the DSSCs. The fabrication of aligned $\mathrm{ZnO}$ nanorods grown on $\mathrm{Sn}$-doped $\mathrm{ZnO}$ thin film is an important contribution of this study.

\section{Conflict of Interests}

The authors declare that there is no conflict of interests regarding the publication of this paper.

\section{Acknowledgments}

This work was supported by Grant no. 600-RMI/DANA 5/3/PSI (165/2013) and RAGS/2013/UITM/TK02/1 (600RMI/RAGS5/3 (52/2013)) from the Ministry of Education Malaysia. The authors would like to thank the Research Management Institute (RMI) UiTM for their support of this research. The authors would also like to thank the NANOElecTronic Centre at Faculty of Electrical Engineering and NANO-SciTech Centre at the Institute of Science for the use of their facilities.

\section{References}

[1] X. D Wang, J. H. Song, and Z. L. Wang, "Nanowire and nanobelt arrays of zinc oxide from synthesis to properties and to novel devices," Journal of Materials Chemistery, vol. 17, pp. 711-720, 2007.

[2] S. Zhu, L. Shan, X. Chen et al., "Hierarchical ZnO architectures consisting of nanorods and nanosheets prepared via a solution route for photovoltaic enhancement in dye-sensitized solar cells," RSC Advances, vol. 3, no. 9, pp. 2910-2916, 2013.

[3] M. Law, L. E. Greene, J. C. Johnson, R. Saykally, and P. Yang, "Nanowire dye-sensitized solar cells," Nature Materials, vol. 4, no. 6, pp. 455-459, 2005.

[4] Y. Shi, C. Zhu, L. Wang et al., "Optimizing nanosheet-based $\mathrm{ZnO}$ hierarchical structure through ultrasonic-assisted precipitation for remarkable photovoltaic enhancement in quasi-solid dye-sensitized solar cells," Journal of Materials Chemistry, vol. 22, no. 26, pp. 13097-13103, 2011.

[5] G. K. Mor, K. Shankar, M. Paulose, O. K. Varghese, and C. A. Grimes, "Use of highly-ordered $\mathrm{TiO}_{2}$ nanotube arrays in dyesensitized solar cells," Nano Letters, vol. 6, no. 2, pp. 215-218, 2006.

[6] M. H. Lai, M. W. Lee, G.-J. Wang, and M. F. Tai, "Photovoltaic performance of new-structure $\mathrm{ZnO}$-nanorod dye-sensitized solar cells," International Journal of Electrochemical Science, vol. 6, pp. 2122-2130, 2011.

[7] D. Bao, H. Gu, and A. Kuang, "Sol-gel-derived c-axis oriented ZnO thin films," Thin Solid Films, vol. 312, no. 1-2, pp. 37-39, 1998.

[8] S. Fujihara, C. Sasaki, and T. Kimura, "Crystallization behavior and origin of $\mathrm{c}$-axis orientation in sol-gel-derived $\mathrm{ZnO} \mathrm{Li}$ thin films on glass substrates," Journal of Applied Surface Science, vol. 180, no. 3-4, pp. 341-350, 2001.

[9] J. H. Lee, P. Lin, J. C. Ho, and C. C. Lee, "Chemical solution deposition of $\mathrm{Zn}_{1-x} \mathrm{Zr}_{x} \mathrm{O}$ thin films as active channel layers of thin-film transistors," Electrochemical and Solid-State Letters, vol. 9, no. 4, pp. G117-G120, 2006.

[10] S. O. Kucheyev, A. J. Biener, Y. M. Wang et al., "Atomic layer deposition of $\mathrm{ZnO}$ on ultralow-density nanoporous silica aerogel monoliths," Applied Physics Letters, vol. 86, no. 8, Article ID 083108, 2005.

[11] S. L. Wang, X. Jia, P. Jiang, H. Fang, and W. H. Tang, "Largescale preparation of chestnut-like $\mathrm{ZnO}$ and $\mathrm{Zn}-\mathrm{ZnO}$ hollow nanostructures by chemical vapor deposition," Journal of Alloys and Compounds, vol. 502, no. 1, pp. 118-122, 2003.

[12] V. Shelke, B. K. Sonawane, M. P. Bhole, and D. S. Patil, "Effect of annealing temperature on the optical and electrical properties of aluminum doped $\mathrm{ZnO}$ films," Journal of Non-Crystalline Solids, vol. 355, no. 14-15, pp. 840-843, 2009.

[13] E. Holemeluad, J. Schou, S. Tauguard, and N. B. Larsen, "Pure and $\mathrm{Sn}$-doped $\mathrm{ZnO}$ films by pulsed laser deposition," Appllied Surface Science, vol. 197, pp. 467-471, 2002.

[14] N. W. Schmidt, T. S. Totushek, W. A. Kimes, D. R. Callender, and J. R. Doyle, "Effects of substrate temperature and near-substrate plasma density on the properties of dc magnetron sputtered aluminum doped zinc oxide," Journal of Applied Physics, vol. 94, no. 9, pp. 5514-5521, 2003.

[15] J. H. Lee and B. Park, "Characteristics of Al-doped ZnO thin films obtained by ultrasonic spray pyrolysis: effects of $\mathrm{Al}$ doping and an annealing treatment," Materials Science and Engineering $B$, vol. 106, no. 3, pp. 242-245, 2004. 
[16] Y. Nan and C. C. Chun, "Investigation of $\mathrm{ZnO}$ nanorods synthesized by a solvothermal method, using Al-doped $\mathrm{ZnO}$ seed films," Optical Materials, vol. 34, no. 4, pp. 753-756, 2012.

[17] Z. H. Chen, Y. B. Tang, Y. Liu et al., "ZnO nanowire arrays grown on $\mathrm{Al}$ : $\mathrm{ZnO}$ buffer layers and their enhanced electron field emission," Journal of Applied Physics, vol. 106, no. 6, Article ID 064303, 2009.

[18] J. Yang, J. Lee, K. Im, and S. Lim, "Influence of Sn-doping in hydrothermal methods on the optical property of the $\mathrm{ZnO}$ nanorods," Physica E, vol. 42, no. 1, pp. 51-56, 2009.

[19] J. H. Lee and B. O. Park, "Transparent conducting ZnO:Al, In, thin films deposited by the sol-gel method," Thin Solid Films, vol. 426, no. 1-2, pp. 94-99, 2003.

[20] K. J. Chen, F. Y. Hung, Y. T. Chen, S. J. Chang, and Z. S. $\mathrm{Hu}$, "Surface characteristics, optical and electrical properties on sol-gel synthesized sn-doped $\mathrm{ZnO}$ thin film," Materials Transactions, vol. 51, no. 7, pp. 1340-1345, 2010.

[21] V. Shelke, B. K. Sonawane, M. P. Bhole, and D. S. Patil, "Electrical and optical properties of transparent conducting tin doped $\mathrm{ZnO}$ thin films," Journal of Materials Science: Materials in Electronics, vol. 23, no. 2, pp. 451-456, 2012.

[22] J. Lee, W. Gaoz, L. M. Hodgson, J. Metson, H. Gong, and U. Pal, "Sputtered deposited nanocrystalline $\mathrm{ZnO}$ films: a correlation between electrical, optical and microstructural properties," Applied Physics A: Materials Science and Processing, vol. 80, no. 8, pp. 1641-1646, 2005.

[23] S. Venkataraj, S. Hishita, Y. Adachi et al., "Structure and electric properties in tin-doped zinc oxide films synthesized by pulsed laser deposition," Journal of the Electrochemical Society, vol. 156, no. 6, pp. H424-H429, 2009.

[24] C.-Y. Tsay, H.-C. Cheng, Y.-T. Tung, W.-H. Tuan, and C.-K. Lin, "Effect of Sn-doped on microstructural and optical properties of ZnO thin films deposited by sol-gel method," Thin Solid Films, vol. 517, no. 3, pp. 1032-1036, 2008.

[25] H. Oh, J. Krantz, I. Litzov, T. Stubhan, L. Pinna, and C. J. Brabec, "Comparison of various sol-gel derived metal oxide layers for inverted organic solar cells," Solar Energy Materials \& Solar Cells, vol. 95, no. 8, pp. 2194-2199, 2011.

[26] Z. Pan, X. Tian, S. Wu et al., "Effects of $\mathrm{Al}$ and Sn dopants on the structural and optical properties of $\mathrm{ZnO}$ thin films," Superlattices and Microstructures, vol. 54, no. 1, pp. 107-117, 2013.

[27] A. Anders, S. H. N. Lim, K. M. Yu et al., "High quality $\mathrm{ZnO}: \mathrm{Al}$ transparent conducting oxide films synthesized by pulsed filtered cathodic arc deposition," Thin Solid Films, vol. 518, no. 12, pp. 3313-3319, 2010.

[28] J. Zhang and W. Que, "Preparation and characterization of solgel Al-doped $\mathrm{ZnO}$ thin films and $\mathrm{ZnO}$ nanowire arrays grown on Al-doped $\mathrm{ZnO}$ seed layer by hydrothermal method," Solar Energy Materials and Solar Cells, vol. 94, no. 12, pp. 21812186, 2010.

[29] X. Tao, M. Fu, A. Zho, D. He, and Y. S. Wang, "The effect of seed layer on morphology of $\mathrm{ZnO}$ nanorod arrays grown by hydrothermal method," Journal of Alloys and compounds, vol. 489, no. 1, pp. 99-102, 2010.

[30] H. K. Lee, M. S. Kim, and J. S. Yu, "Effect of AZO seed layer on electrochemical growth and optical properties of $\mathrm{ZnO}$ nanorod arrays on ITO glass," Nanotechnology, vol. 22, no. 44, Article ID 445602, 2011.

[31] M. Kao, H. Chen, S. Young, C. Lin, and C. Kung, "Structure and photovoltaic properties of Zno nanowire for dye-sensitized solar cells," Nanoscale Research Letters, vol. 7, article 260, 2012.
[32] W. Yang, F. Wan, S. Chen, and C. Jiang, "Hydrothermal growth and application of $\mathrm{ZnO}$ nanowire films with $\mathrm{ZnO}$ and $\mathrm{TiO}_{2}$ buffer layers in dye-sensitized solar cells," Nanoscale Research Letters, vol. 4, pp. 1486-1492, 2009.

[33] Y. F. Gao, M. Nagai, T. C. Chang, and J. J. Shyue, "Solutionderived $\mathrm{ZnO}$ nanowire array film as photoelectrode in dyesensitized solar cells," Crystal Growth and Design, vol. 7, no. 12, pp. 2467-2471, 2007. 

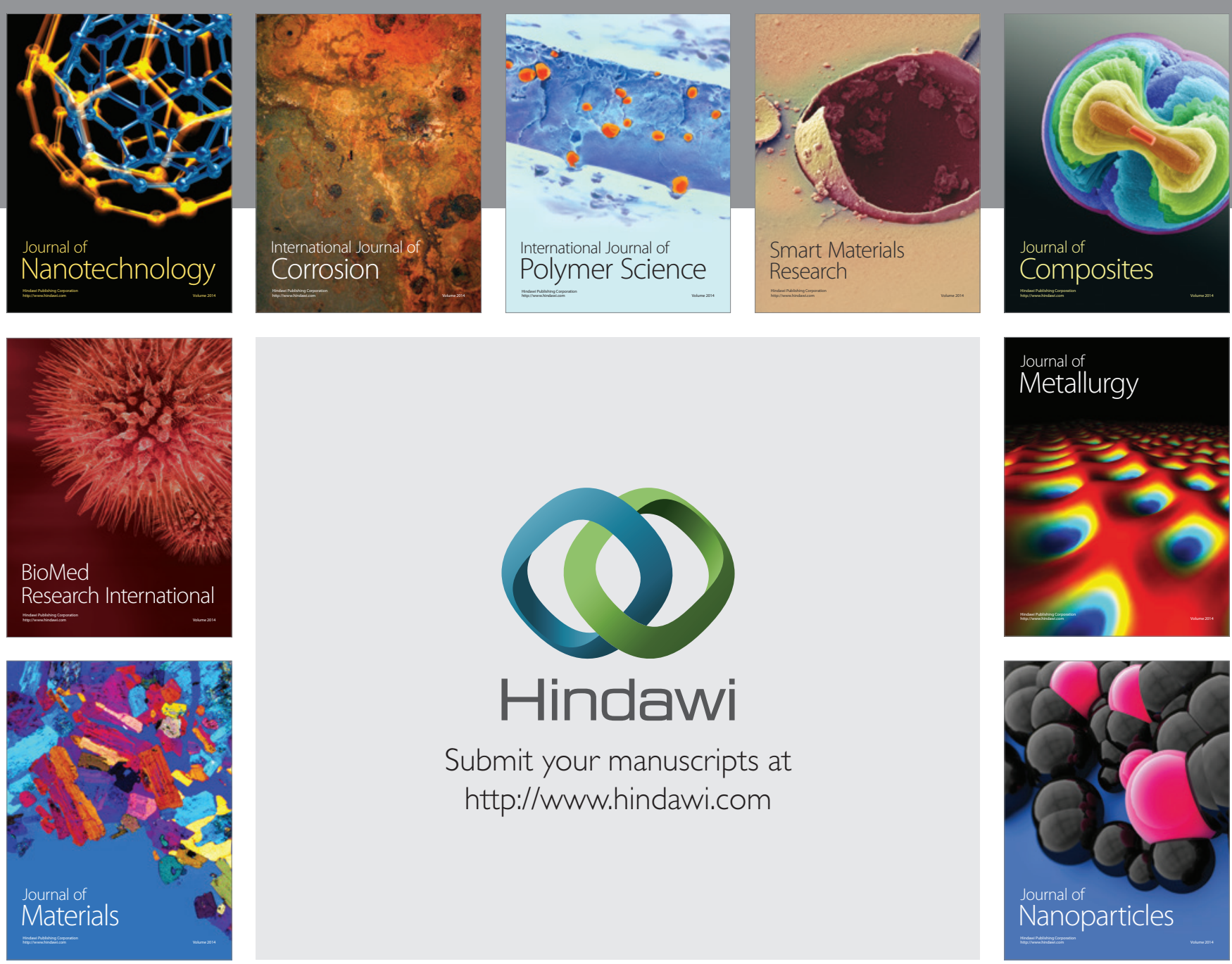

Submit your manuscripts at http://www.hindawi.com
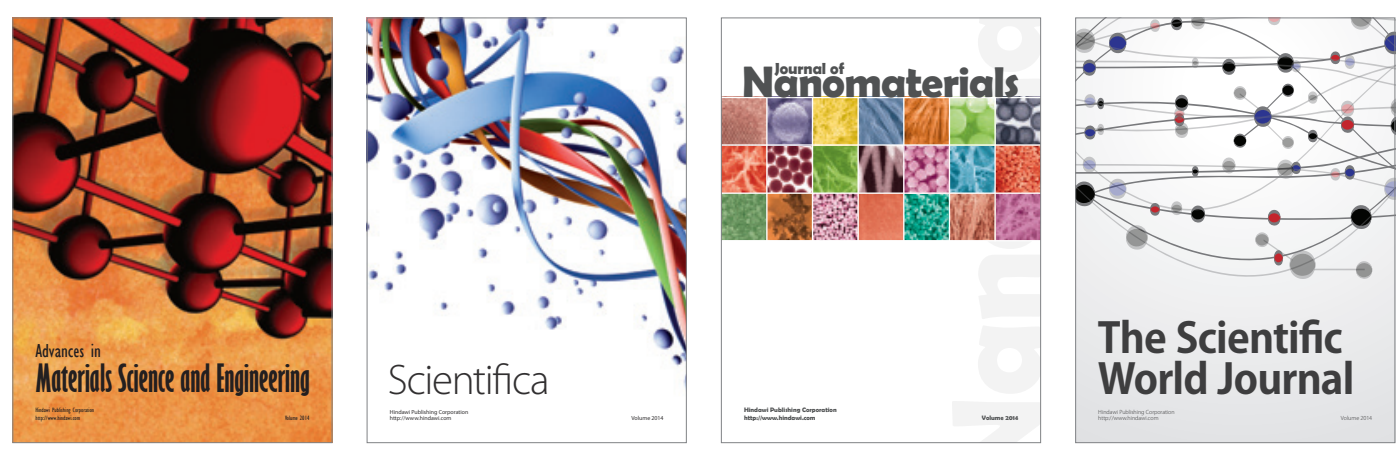

\section{The Scientific World Journal}
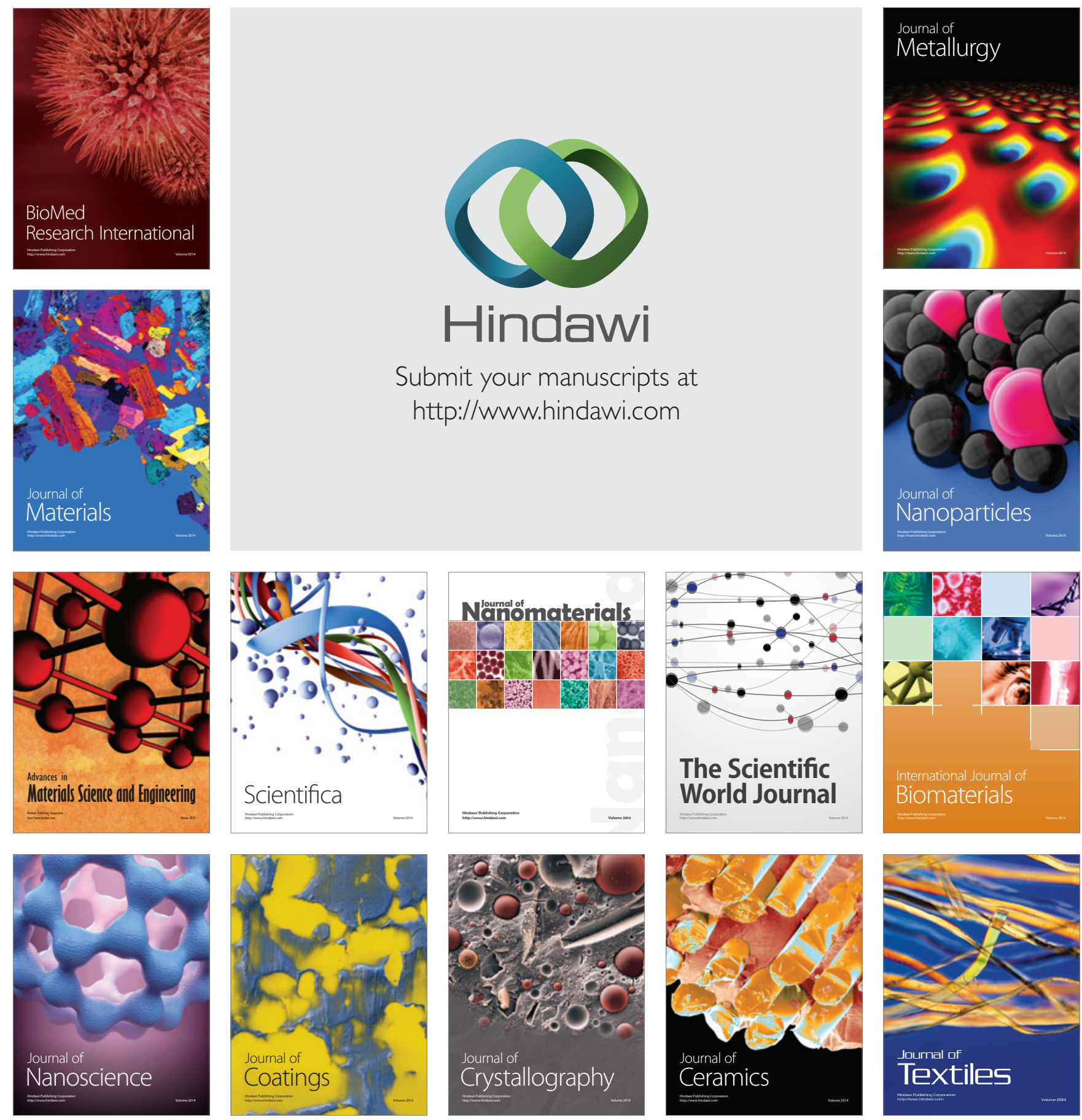